\title{
DYNAMIC ANALYSIS OF REINFORCED CONCRETE STRUCTURES
}

\section{ANÁLISIS DINÁMICO DE ESTRUCTURAS DE CONCRETO ARMADO}

\author{
Jorge L. P. Tamayo ${ }^{1}$, Armando M. Awruch², Inácio B. Morsch ${ }^{3}$
}

\begin{abstract}
The objective of this work is to provide a reliable numerical model using the finite element method (FEM) for the dynamic analysis of reinforced concrete $(R C)$ structures. For this purpose, a computer program based on a strain-rate sensitive elasto-plastic theory is developed using $3 D$ brick finite elements. The implicit Newmark scheme with predictor and corrector phases is used for time integration of the nonlinear system of equations. In addition, the steel reinforcement is considered to be smeared and perfectly adhered to concrete and represented by membrane finite elements. Two benchmark examples are analyzed with the present numerical model and results are compared with those obtained by other authors. The present numerical model is able to reproduce the path failure, collapse loads and failure mechanism within an acceptable level of accuracy.
\end{abstract}

Keywords: Reinforced concrete (RC) structures, Finite element method (FEM).

\section{RESUMEN}

El objetivo de este trabajo es presentar un modelo numérico confiable usando el método de los elementos finitos (MEF) para el análisis dinámico de estructuras de concreto reforzado. Con este propósito, un programa de cómputo basado en la teoría de elasto-plasticidad con sensibilidad a la velocidad de deformación es desarrollado usando elementos finitos tridimensionales. El procedimiento de Newmark es adoptado para la integración en el tiempo del sistema no linear de ecuaciones. Además, se supone que el acero de refuerzo está perfectamente distribuido e adherido al concreto, siendo representado por elementos finitos de membrana. Dos ejemplos son solucionados con el presente modelo numérico y los resultados obtenidos son comparados con los resultados de otros autores. Para todos los casos, la trayectoria de falla, la carga de colapso y el mecanismo de falla son reproducidos con suficiente precisión.

Palabras clave.- Estructuras de concreto reforzado, Método de los elementos finitos (MEF).

\section{INTRODUCTION}

Nonlinear analysis of reinforced concrete structures is an important subject nowadays. Any reinforced concrete structural system may be subjected to dynamic loading during its life.
Understanding of the structural response to such load is essential in order to protect infrastructure. For this purpose, mathematical models for predicting the behaviour of concrete under dynamic loading are formulated in this work.

\footnotetext{
1Ingeniero egresado de la Facultad de Ingeniería Civil de la Universidad Nacional de Ingeniería, Magister e investigador en la Universidad Federal do Rio Grande do Sul - Brazil, 2Doctor en ciencias, profesor e investigador en la Universidad Federal do Rio Grande do Sul - Brazil, 3Doctor en ciencias, profesor e investigador en la Universidad Federal do Rio Grande do Sul - Brazil.
} 
Moreover, due to infinite number of permutations of structural parameters and due to the cost of experimental test, it is desirable to employ a numerical tool for the prediction of the structural response. In this work, a computer code based on a displacement approach is developed using 3D brick elements (see Fig. 1).

Reliability of the present numerical code is demonstrated by the solution of two well-known examples.

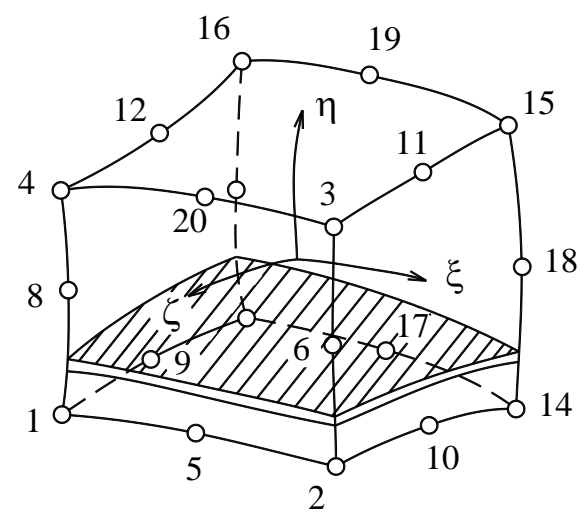

Fig. 1 20-node brick element.

\section{FINITE ELEMENT FORMULATION AND CONSTITUTIVE MODEL}

The 20-node isoparametric quadratic brick element is used here to represent the concrete structure where the reinforcement bars are modelled using the smeared layer approach.

The displacement field within the element is defined in terms of the shape functions and displacement values at the nodes.

Each nodal point has three degrees of freedom $u$, $v$ and $w$ along the $\operatorname{cartesian} x, y$ and $z$ coordinates, respectively.

Therefore, for each element the displacement vector is expressed in the following manner:

$\{U\}_{b}=\left\{u_{1}, v_{1}, w_{1}, u_{2}, v_{2}, w_{2} \ldots . u_{20}, v_{20}, w_{20}\right\}$

The strain components vector is defined by:

$$
\{\varepsilon\}=\left\{\begin{array}{c}
\varepsilon_{x} \\
\varepsilon_{y} \\
\varepsilon_{z} \\
\gamma_{x y} \\
\gamma_{y z} \\
\gamma_{x z}
\end{array}\right\}=\sum_{k=1}^{20}\left[\begin{array}{ccc}
\frac{\partial N_{k}}{\partial x} & 0 & 0 \\
0 & \frac{\partial N_{k}}{\partial y} & 0 \\
0 & 0 & \frac{\partial N_{k}}{\partial z} \\
\frac{\partial N_{k}}{\partial y} & \frac{\partial N_{k}}{\partial x} & 0 \\
0 & \frac{\partial N_{k}}{\partial z} & \frac{\partial N_{k}}{\partial y} \\
\frac{\partial N_{k}}{\partial x} & 0 & \frac{\partial N_{k}}{\partial z}
\end{array}\right]\left\{\begin{array}{c}
u_{k} \\
v_{k} \\
w_{k}
\end{array}\right\}
$$

or

$$
\{\varepsilon\}_{b}=[B]_{b}\{U\}_{b}
$$

where $N_{k}$ is the shape function of node $k$ and $[B]_{b}$ is the strain-displacement matrix. The stresses and strains are related by the following expression:

$$
\begin{aligned}
& \{\boldsymbol{\sigma}\}_{b}= \\
& {\left[\begin{array}{llllll}
\sigma_{x} & \sigma_{y} & \sigma_{z} & \tau_{x y} & \tau_{y z} & \tau_{x z}
\end{array}\right]^{T}=[D]\{\varepsilon\}_{b}}
\end{aligned}
$$

where $[D]$ is the material constitutive matrix in the global system. Equivalent nodal forces, at given iteration $i$, are expressed in the following form:

$$
\{P\}_{b}^{i}=\int_{V}[B]_{b}^{T}\{\sigma\}_{b}^{i} d V
$$

The stiffness matrix for a concrete element of volume $V$ can be expressed as:

$$
[K]_{b}^{i}=\int_{V}[B]_{b}^{T}[D]_{e t}^{i}[B]_{b} d V
$$

where $[D]_{e t}^{i}$ is the uncracked, cracked or elastoplastic constitutive matrix for the concrete material and the elastic or elasto-plastic constitutive matrix for the steel reinforcement. An integration rule of 15 points is found to be suitable to diminish shear locking effect. Concrete in compression is modeled using the associated theory of plasticity; a modified Drucker-Prager yield criterion (see Fig. 2), which was proposed by Cervera et al. [1], is used in this work. Due to nonlinear hardening behavior, this yield criterion defines an initial yield surface at an effective stress equal to $\sigma_{0}=0.3 f_{c}$ (which is the beginning of the plastic deformation) and a limit 
surface separating a nonlinear state from a perfect elasto-plastic one, as it is shown in Fig. 3. The yield criterion is defined as:

$F(\sigma)=c I_{1}+\left\{c^{2} I_{1}^{2}+3 m J_{2}\right\}^{1 / 2}=\sigma_{o}\left(\bar{\varepsilon}_{p}\right)$

where $I_{1}$ and $J_{2}$ are the first and the deviatoric second stress invariants, respectively. In addition, $\sigma_{0}$ is the effective stress which depends on the effective plastic deformation $\bar{\varepsilon}_{p}$, being this last parameter defined in terms of the plastic work developed by the material. The constants $c$ and $m$ are evaluated from experimental test and are equal to 0.1775 and 1.355 , respectively. The associated flow rule is defined as:

$d \varepsilon_{i j}^{p}=$

$d \lambda \frac{\partial F(\sigma)}{\partial \sigma_{i j}}=\frac{\{g\}^{T}[D]_{e}}{H^{\prime}+\{g\}^{T}[D]_{e}\{g\}}\{d \varepsilon\} \frac{\partial F(\sigma)}{\partial \sigma_{i j}}$

with the flow vector given by:

$\{g\}^{T}=\left[\begin{array}{lllll}\frac{\partial F}{\partial \sigma_{x}} & \frac{\partial F}{\partial \sigma_{y}} & \frac{\partial F}{\partial \sigma_{x y}} & \frac{\partial F}{\partial \sigma_{x z}} & \frac{\partial F}{\partial \sigma_{y z}}\end{array}\right]$ (9)

In Equation (8), $\{d \varepsilon\}$ contains the components of the total strain, $d \varepsilon_{i j}^{p}$ is a component of the plastic strain tensor, $[D]_{e}$ is the elastic constitutive matrix and $H^{\prime}$ is the hardening parameter established as the slope of the uniaxial curve which defines the hardening rule. This curve known as "Madrid parabola" is defined by the following expression:

$$
\sigma_{y}=H\left(\bar{\varepsilon}_{p}\right)=E_{c} \bar{\varepsilon}_{p}+\left(2 E_{c}^{2} \varepsilon_{o} \bar{\varepsilon}_{p}\right)^{1 / 2}
$$

where $E_{c}$ is the elastic modulus, $\varepsilon_{o}$ represents the total strain at maximum compression stress $f_{c}$. The elasto-plastic constitutive relation is expressed in the following differential form:

$$
\begin{aligned}
& \{d \sigma\}= \\
& {[D]_{e t}\{d \varepsilon\}=\left\{[D]_{e}-\frac{[D]_{e}\{g\}\{g\}^{T}[D]_{e}}{H^{\prime}+\{g\}^{T}[D]_{e}\{g\}}\right\}\{d \varepsilon\}}
\end{aligned}
$$

where $[D]_{e t}$ is the elasto-plastic constitutive matrix. Finally, the crushing condition is given by:

$$
c I_{1}^{\prime}+\left\{c^{2} I_{1}^{\prime 2}+3 m J_{2}^{\prime}\right\}^{1 / 2}=\varepsilon_{u}
$$

where $I_{1}^{\prime}$ and $J_{2}^{\prime}$ are the first and the deviatoric second strain invariants, respectively and $\varepsilon_{u}$ represents the ultimate deformation extrapolated from experimental test (it is taken here as 0.0035).

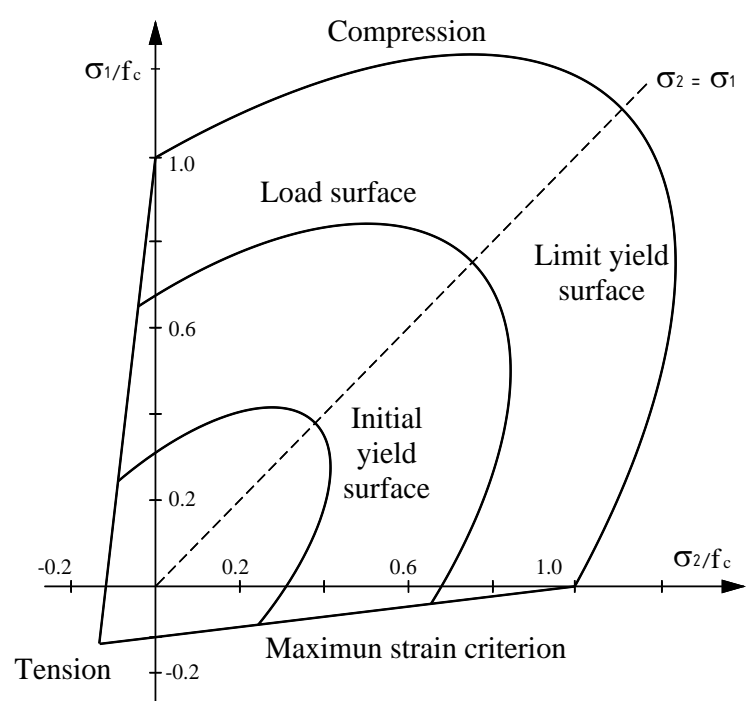

Fig. 2 Bi-axial representation of constitutive model for concrete.

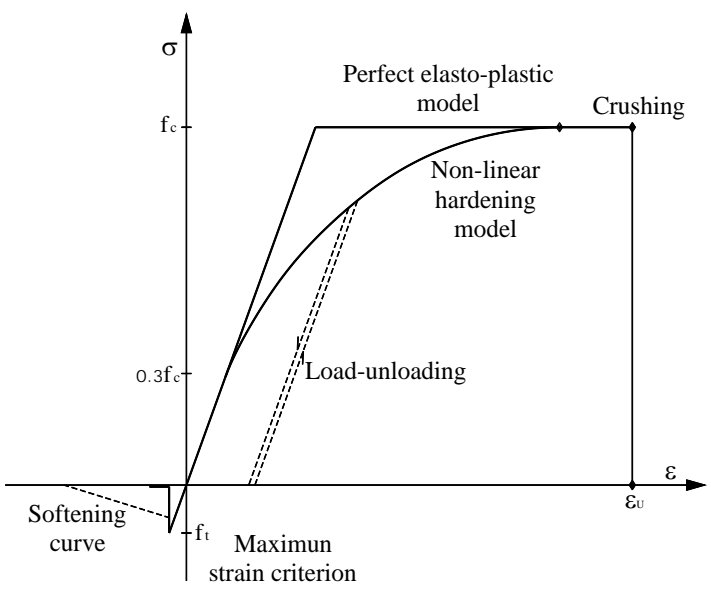

Fig. 3 Uni-axial representation of constitutive model for concrete.

Earlier developments and studies suggest that a concrete model intended for transient analysis 
should be rate and history dependent. To describe rate effects, the constitutive law, which was first introduced in Equation (7), can be rewritten as:

$$
\sigma_{o d}=\sigma_{o}\left(\bar{\varepsilon}_{p}\right)\left\{1+0.0279\left(\frac{\dot{\varepsilon}}{10^{-5}}\right)^{0.3302}\right\}
$$

in which $\sigma_{o d}$ is now a yield function both of the strain history and the current strain rate $\dot{\varepsilon}$. The reader is referred to the work of Liu and Owen [2] for a detailed explanation of this consideration. Otherwise, because the cracking tensile strain of concrete is almost invariably in dynamic loading, the cracking is governed by a maximum tensile strain criterion. Then, the response of concrete under tensile stresses is assumed to be linear elastic until the fracture surface is reached (see Fig. 2) and then, its behavior is characterized by an orthotropic material. Cracks are assumed to occur in planes perpendicular to the direction of the maximum tensile strain as soon as this strain reaches the specified concrete tensile strain $\varepsilon_{c t}$.

After cracking has occurred the elastic modulus and Poisson's ratio are assumed to be zero in the perpendicular direction to the cracked plane, and a reduced shear modulus is employed. Due to bond effects, cracked concrete carries, between cracks, a certain amount of tensile force normal to the cracked plane. This effect is considered through a relationship between the strain and the stress normal to the cracking plane direction, as shown in Fig. 4. For more details of this algorithm, the reader is referred to reference [3].

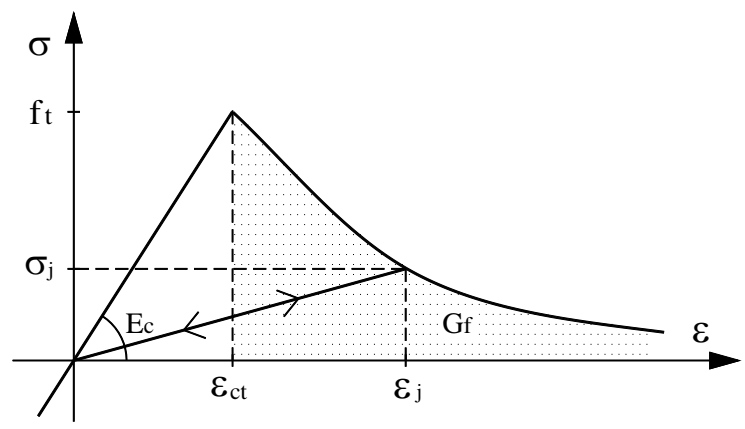

Fig. 4 Tension stiffening model.

In Fig. $4 f_{t}$ is the maximum tensile stress associated to the tensile strain $\varepsilon_{c t}$ and the normal stress $\sigma_{j}$ is determined from the current strain $\varepsilon_{j}$ as established in the following expression:

$$
\sigma=f_{t} e^{\frac{-\left(\varepsilon_{j}-\varepsilon_{c t}\right)}{\alpha}}
$$

where $\alpha$ is a softening parameter obtained from the concept of fracture energy of concrete $G_{f}$.

The use of the fracture energy guarantees that the numerical response will be independent of the finite element mesh [1].

The steel reinforcement is modeled as an uniaxial elasto-plastic material with a constant elastic modulus $E_{s}$ and a tangential modulus $E_{s^{\prime}}$ according to the bilinear stress-strain relation shown in Fig. 5.

This relation is the same for tension and compression stresses and hysteretic loops are allowed to be formed.

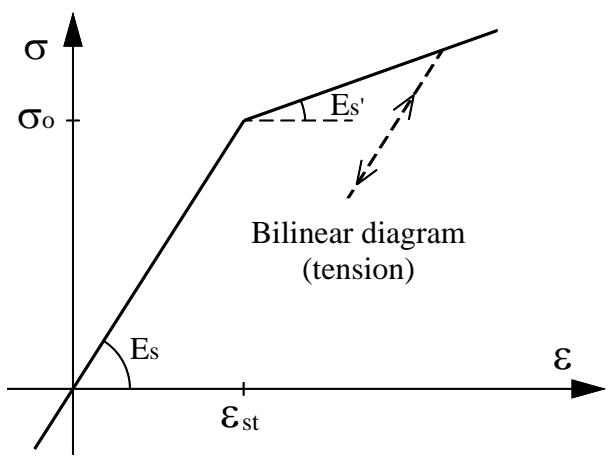

Fig. 5 Constitutive law for steel.

\section{NUMERICAL ALGORITHM}

In order to introduce the implicit numerical algorithm for the solution of the nonlinear dynamic equation, it is necessary to describe the predictor and corrector form of the Newmark scheme for the integration of the semi-discrete system of governing equations.

Typically at time station $t_{n+1}$ these equations take the following form: 


$$
\begin{aligned}
& {[M]\{a\}_{n+1}+[C]\{v\}_{n+1}+} \\
& \quad \int[B]^{T}\{\sigma\}_{n+1}\left(d_{n+1}\right) d \Omega=f_{n+1}
\end{aligned}
$$

where $[M]$ and $[C]$ are the mass and damping matrices, respectively while $\{a\}_{n+1},\{v\}_{n+1}$ and $\{d\}_{n+1}$ are the acceleration, velocity and displacement vectors, respectively. The tangential stiffness matrix $[K]_{e t}$ is related to the internal forces in the following manner:

$[K]_{e t}\{\Delta d\}_{n}=$

$\int[B]^{T}\{\sigma\}_{n+1}\left(d_{n+1}\right) d \Omega-\int[B]^{T}\{\sigma\}_{n}\left(d_{n}\right) d \Omega$

with

$$
K_{e t}=\int[B]^{T}[D]_{e p}[B] d \Omega
$$

In the Newmark scheme the displacement and velocity at time $t_{n+1}$ can be expressed in the following form:

$$
\begin{gathered}
\{d\}_{n+1}=\{\tilde{d}\}_{n+1}+\Delta t^{2} \beta\{a\}_{n+1} \\
\{v\}_{n+1}=\{\tilde{v}\}_{n+1}+\Delta t \gamma\{a\}_{n+1}
\end{gathered}
$$

with

$$
\begin{gathered}
\{\tilde{d}\}_{n+1}=\{d\}_{n}+\Delta t\{v\}_{n}+\Delta t^{2}(1 / 2-\beta)\{a\}_{n+1} \\
\{\tilde{v}\}_{n+1}=\{v\}_{n}+\Delta t(1-\gamma)\{a\}_{n}
\end{gathered}
$$

Note that $\{d\}_{n},\{d\}_{n+1}$ and $\{d\}_{n+1}$ are the approximations to $d\left(t_{n}\right), \dot{d}\left(t_{n}\right)$ and $\ddot{d}\left(t_{n}\right)$ and $\beta$ and $\gamma$ are free parameters which control the accuracy and stability of the method. $\{\tilde{d}\}_{n+1}$ and $\{\tilde{v}\}_{n+1}$ are the predictor values and $\{d\}_{n+1}$ and $\{v\}_{n+1}$ are the corrector values. Initially the displacements $\quad\{d\}_{0}$ and velocities $\quad\{v\}_{0}$ are provided and the acceleration $\{a\}_{0}$ is obtained from the following expression:

$$
[M]\{a\}_{0}=f_{0}-[C]\{v\}_{0}-[K]_{e}\{d\}_{0}
$$

By using Equation (15) to Equation (21), an effective static problem is formed which is solved using a Newton Raphson type scheme.
This algorithm is summarized in Table 1.

Table 1. Newmark's algorithm.

1 Set iteration counter $i=0$

2 Begin predictor phase in which we set

$$
\begin{aligned}
& \{d\}_{n+1}^{i}=\{\tilde{d}\}_{n+1}=\{d\}_{n} \\
& \{v\}_{n+1}^{i}=\{\tilde{v}\}_{n+1}=\{v\}_{n} \\
& \{a\}_{n+1}^{i}=\left(\{d\}_{n+1}^{i}-\{\tilde{d}\}_{n+1}\right) /\left(\Delta t^{2} \beta\right)
\end{aligned}
$$

3 Evaluate residual forces

$$
\begin{aligned}
& \{\psi\}^{i}=\{f\}_{n+1}-[M]\{a\}_{n+1}^{i}- \\
& {[C]\{v\}_{n+1}^{i}-\int[B]^{T}\{\sigma\}_{n+1}^{i}\left(\{d\}_{n+1}^{i}\right) d \Omega}
\end{aligned}
$$

4 If required, form the effective stiffness matrix using the expression:

$$
\begin{aligned}
& {[K]^{*}=} \\
& {[M] /\left(\Delta t^{2} \beta\right)+\gamma[C]_{T} /(\Delta t \beta)+[K]_{T}\left(d_{n+1}^{i}\right)}
\end{aligned}
$$

Otherwise use a previously calculated $K^{*}$

5 Factorize, forward reduction and back substitute as required to solve

$$
[K]^{*} \cdot\{\Delta d\}^{i}=\{\psi\}^{i}
$$

6 Enter corrector phase in which we set

$$
\begin{aligned}
& \{d\}_{n+1}^{i+1}=\{d\}_{n+1}^{i}+\{\Delta d\}^{i} \\
& \{a\}_{n+1}^{i+1}=\left(\{d\}_{n+1}^{i}-\{\tilde{d}\}_{n+1}\right) /\left(\Delta t^{2} \beta\right) \\
& \{v\}_{n+1}^{i+1}=\{v\}_{n}+\Delta t \gamma\{a\}_{n+1}^{i+1}
\end{aligned}
$$

7 If $\Delta d^{i}$ and/or $\psi^{i}$ do not satisfy the convergence conditions then set $i=i+1$ and go to step 3, Otherwise continue.

Set

$$
\begin{aligned}
& \{d\}_{n+1}=\{d\}_{n+1}^{i+1} \\
& \{v\}_{n+1}=\{v\}_{n+1}^{i+1} \\
& \{a\}_{n+1}=\{a\}_{n+1}^{i+1}
\end{aligned}
$$

To use in the next time step. Also set $\mathrm{n}=\mathrm{n}+1$, form $C v_{n+1}+\int B^{T} \sigma_{n+1}\left(d_{n+1}\right) d \Omega$ and begin the next time step 


\section{APPLICATIONS}

\section{Simply supported beam}

A simply supported reinforced concrete beam shown in Fig. 6 is subjected to two symmetrically applied concentrated loads which are applied as step loads with a zero rise time. The problem has been solved by Beshara and Virdi [4] and Cervera et al. [1]. The beam is reinforced in the lower position by 2 in $^{2}\left(1290 \mathrm{~mm}^{2}\right)$ steel area. The material properties are listed in Table 2. Using symmetry conditions only one half of the beam is modeled using five 20-node isoparametric brick elements with an embedded membrane element to simulate the steel reinforcement. The dynamic analysis is evaluated with a time step of $0.0005 \mathrm{sec}$. No viscous damping is considered. As a check, an elastic analysis (which is not shown here) was first performed, and the results found here are in excellent agreement with those given in reference [1]. In Fig. 7, the central deflection history of the nonlinear case, considering and neglecting the strain-rate sensitive model compares well with the results obtained by Cervera et al. [1] who used a strain-rate sensitive elasto-viscoplastic model.

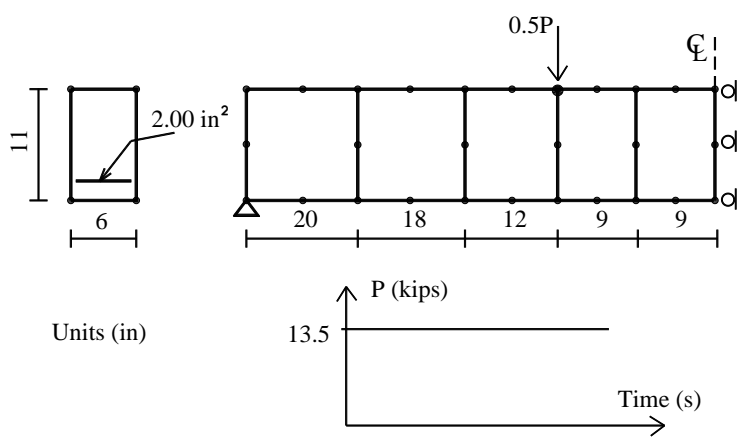

Fig. 6 ADINA reinforced concrete beam subjected to point loads.

In Fig. 8, results obtained by Beshara and Virdi [4] using an elasto-viscoplastic with and without a strain-rate sensitive model are depicted.

These results are used as a base of comparison to see the effect of the rate sensitive model. Some differences are encountered with the present results because in the given reference a different time step was used, but the overall profile response is quite similar. As expected, the use of a strain-rate sensitive model decreases the central deflection.
Table 2. Material properties.

\begin{tabular}{lll}
\hline Material & $\begin{array}{l}\text { Beam } \\
\text { Kip, in (N, mm) }\end{array}$ & $\begin{array}{l}\text { Power plant } \\
\mathrm{N}, \mathrm{mm}\end{array}$ \\
\hline Concrete & & \\
$E_{c}$ & $6100.0(42059.5)$ & 28000.0 \\
$v$ & 0.20 & 0.20 \\
$f_{c}$ & $3.74(25.8)$ & 35.0 \\
$\varepsilon_{u}$ & 0.0035 & 0.0035 \\
$\varepsilon_{c t}$ & $0.750 \mathrm{E}-04$ & $1.50 \mathrm{E}-04$ \\
$\rho$ & $0.217 \mathrm{E}-06(193.2)$ & $0.245 \mathrm{E}-08$ \\
Steel & $30000.0(206850.0)$ & 210000.0 \\
$E_{s}$ & $44.0(303.4)$ & 460.0 \\
$\sigma_{y}$ & $0.0(0.0)$ & 0.0 \\
$H^{\prime}$ & & \\
\hline
\end{tabular}

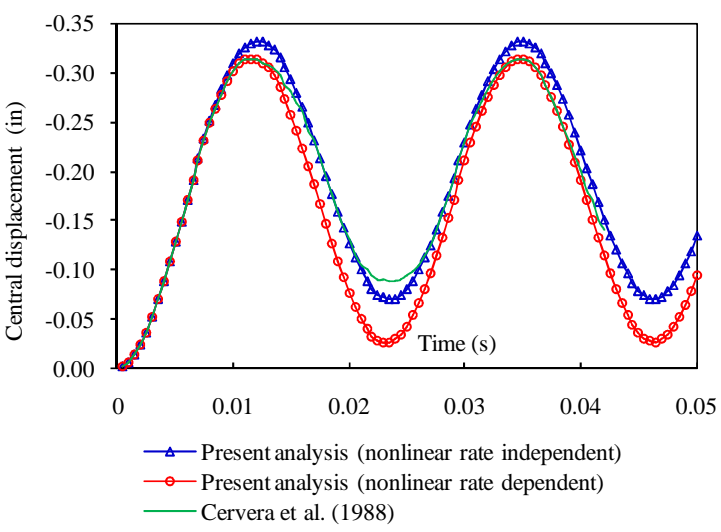

Fig. 7 The effect of strain rate on the nonlinear response of the beam for the present model.

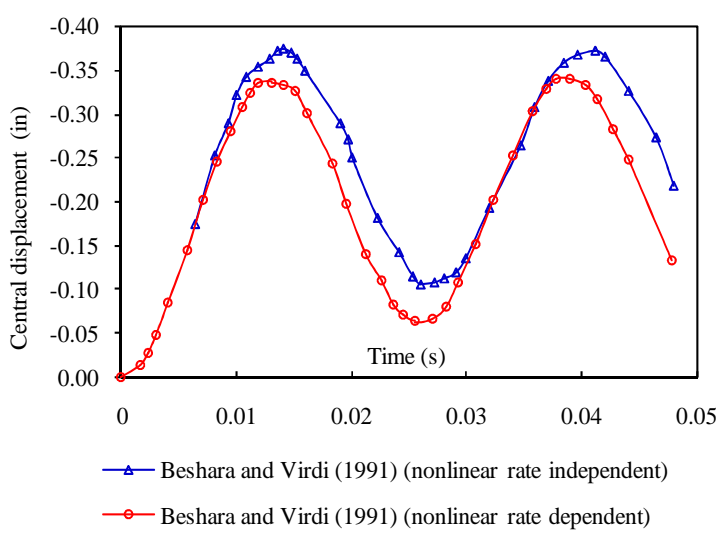

Fig. 8 The effect of strain rate on the nonlinear response of the beam by reference [4]. 


\section{Aircraft impact on nuclear power plant}

The horizontal impact of an aircraft on the shield building of a nuclear power plant is analyzed (see Cervera et al. [1]). The geometry, the loading function and the reinforcement are specified in Fig. 9. The built-in reinforced concrete shell is composite of cylindrical and spherical parts of constant thickness. The reinforcement placed circumferentially and meridionally on the interior and exterior surfaces consist of bars of $40 \mathrm{~mm}$ diameter, spaced at $8 \mathrm{~cm}$. The material properties are shown in Table 2. The impact is assumed to occur horizontally. The location of the area of impact of $28 \mathrm{~m}^{2}$ is also shown in Fig. 9. The load history is also indicated and it is noted that the load has a maximum value of 9000 ton. Since the loading and geometry of the shell are symmetric, only one half of the structure is modeled.

A mesh of 54 solid elements is used in the analysis, with a local refinement in the vicinity of the impact load (see Fig. 10) where a rectangular area of $14 \mathrm{~m}^{2}$ is defined to apply the distributed load. The implicit Newmark scheme with $\beta=0.25$ and $\gamma=0.5$ is used to integrate in time with a time step $\Delta t=0.00475$.

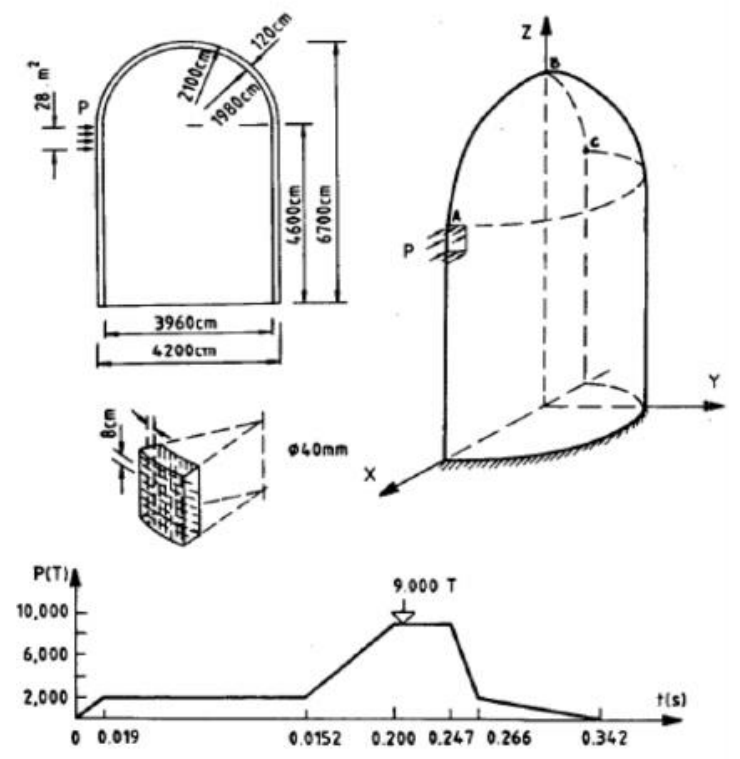

Fig. 9 Nuclear containment structure: general layout and loading time history for aircraft impact taken from reference [1].

Horizontal displacements at points A, B and C are plotted as functions of time in Fig. 11, Fig. 12 and Fig 13, respectively. Two different values of cracking strain are considered here $(0.0015$ and $0.00185)$. In order to compare similar profiles of displacements (see Fig. 11), the response obtained using a cracking strain value 0.00185 is compared directly to that obtained by Cervera and Hinton [5] using a cracking value 0.0020 because it yields approximately the same peak displacement at time 0.274 s. It is important to emphasize that some differences are expected due to the slightly different mesh used and because of the great sensibility of the response at the impact zone due to cracking. That is, a small variation in the value of the cracking strain could yield significant changes in displacements. Another fact to take into account in the final response is the sensibility established by the type of the integration rule used. Results obtained at point B are also expected to be slightly different because the finite element mesh presents a small circular opening at the upper part of the dome. In general, the profile patterns and magnitude of displacements at the three different locations are in good agreement with those presented by Cervera and Hinton [5].

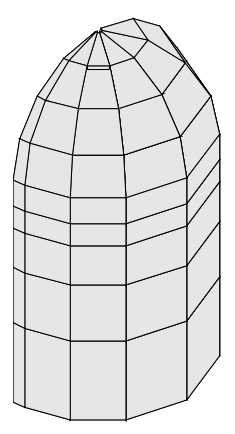

b)

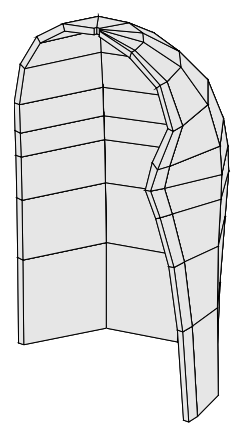

Fig. 10 Finite element mesh with 54 brick elements: a) Initial mesh; b) Magnified deformed mesh at peak displacement.

\section{CONCLUSIONS}

In this work, an elasto-plastic explicit algorithm is used to predict the dynamic behavior of reinforced concrete structures under dynamic loading. Validation of the present algorithm and code is provided by modeling two usual benchmark examples found in the technical literature about this topic. 

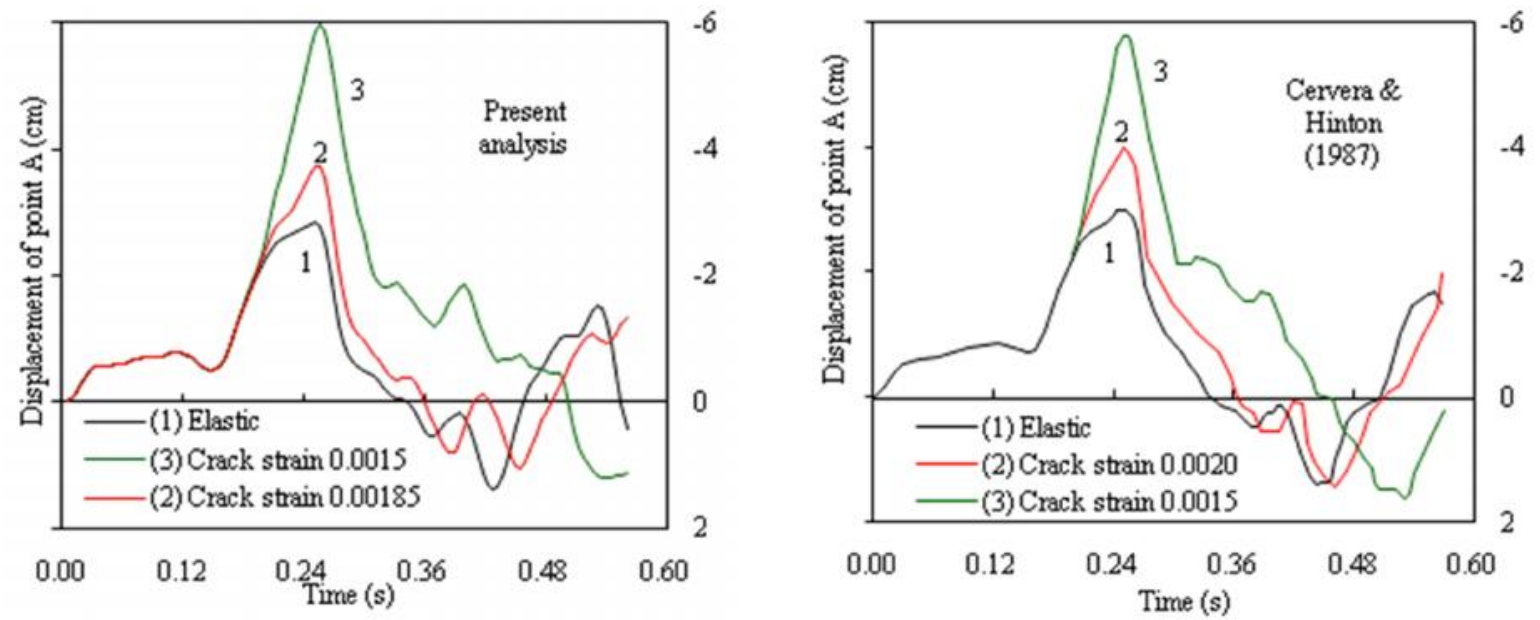

Fig. 11 Horizontal displacement of point A for different cracking strain values $\left(G_{f}=0.2 \mathrm{Kg} / \mathrm{cm}\right)$.
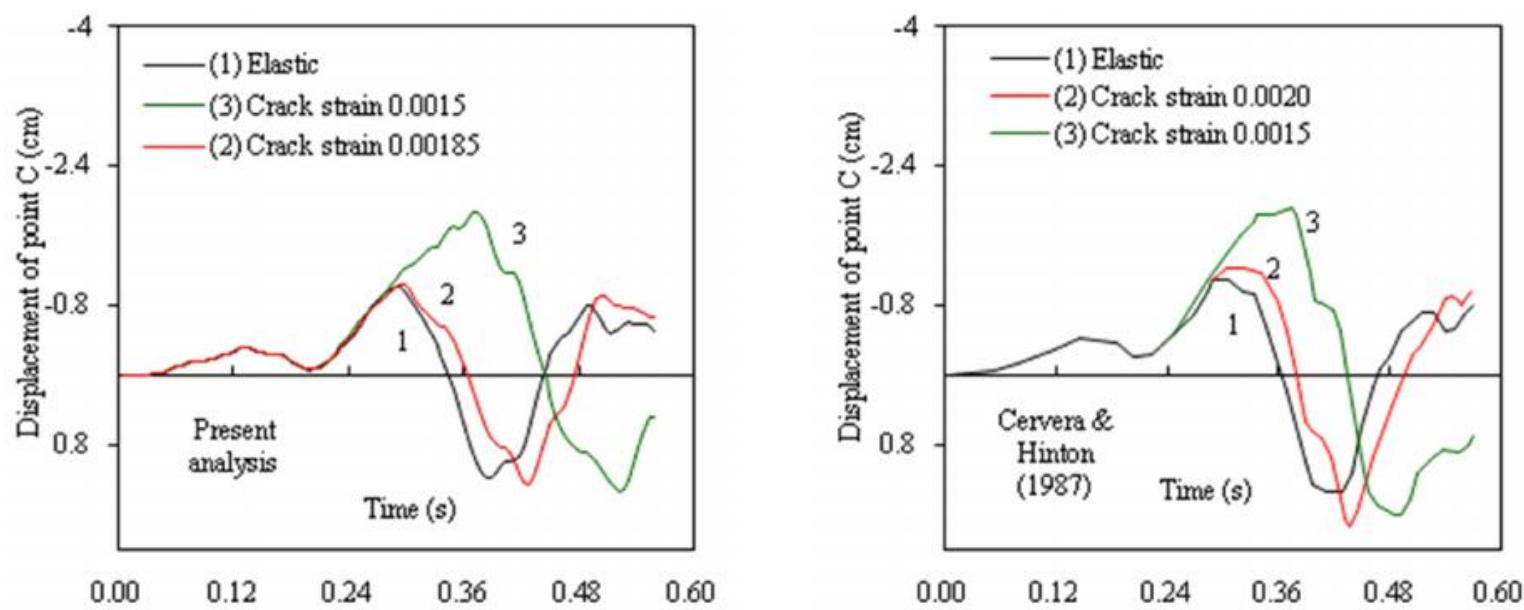

Fig. 12 Horizontal displacement of point B for different cracking strain values $\left(G_{f}=0.2 \mathrm{Kg} / \mathrm{cm}\right)$.
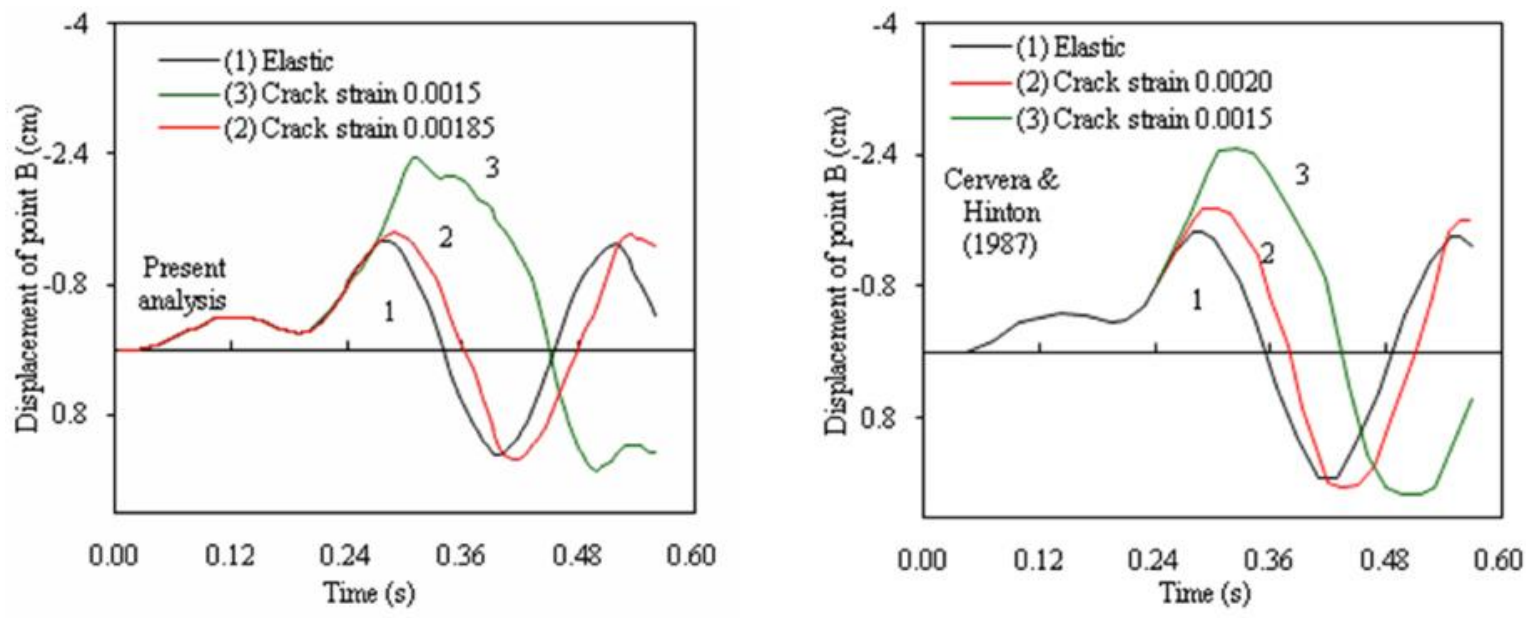

Fig. 13 Horizontal displacement of point $C$ for different cracking strain values $\left(G_{f}=0.2 \mathrm{Kg} / \mathrm{cm}\right)$. 
The strain-rate sensitive model yields logical results and prove to follow the same profile obtained by Beshara and Virgi [4] for the beam. Also, this rate effect was found to be more important where compression dominates. The present elasto-plastic model presented in this work seems to be more advantageous when compared to the strain-rate sensitive elasto-viscoplastic model presented in Cervera et al. [1] because fewer model parameters are needed. For the dynamic analysis of the nuclear power plant, the final displacement response is very sensitive to the way in which cracking develops within the impact zone, where the strain rate effect is not dominant. Further investigation will be carried out to include other effects such as concrete creep and shrinkage and also the inclusion of pre-stressed tendons in the numerical model.

\section{ACKNOWLEDGEMENTS}

The financial support provided by CAPES and CNPQ is gratefully acknowledged.

\section{Notation}

$a \quad$ : Global acceleration vector

$B \quad$ : Strain-displacement matrix

$C \quad$ : Damping matrix

c : Constant

d : Global displacement vector

$D \quad$ : Constitutive matrix

E : Young's modulus

$F \quad$ : Yield function

$g \quad$ : Flow vector

$H^{\prime} \quad$ : Hardening parameter

$I_{1} \quad$ : Fist stress invariant

$I_{1}^{\prime} \quad$ : Fist strain invariant

$J_{2} \quad$ : Deviatoric second stress invariant

$J_{2}^{\prime} \quad$ : Deviatoric second strain invariant

$K \quad$ : Stiffness matrix

$N \quad$ : Shape function

$P \quad:$ Nodal equivalent forces

$v \quad:$ Global velocity vector

$t \quad$ : Time

$U \quad$ : Element displacement vector

$u \quad$ : Displacement

$V \quad$ : Volume

$v \quad:$ Displacement $w \quad$ : Displacement

$x \quad$ : Global coordinate

$y \quad$ : Global coordinate

$z \quad$ : Global coordinate

$\alpha \quad$ : Newmark's coefficient

$\gamma \quad$ : Newmark's coefficient

$\Delta \quad$ : Increment

$\varepsilon \quad:$ Strain

$\bar{\varepsilon} \quad:$ Effective strain

$\dot{\varepsilon} \quad:$ Strain rate

$\psi \quad$ : Unbalanced loads

$\sigma \quad$ : Normal stress

$\tau \quad:$ Shear stress

$\rho \quad$ : Mass density

\section{Subscripts}

$\begin{array}{ll}b & : \text { Brick } \\ c & : \text { Concrete } \\ e t & : \text { Tangential } \\ i & : \text { Current iteration } \\ k & : k_{\text {th }} \text { node } \\ n & : \text { Time station } \\ p & : \text { Plastic } \\ y & : \text { Yielding } \\ u & : \text { Ultimate }\end{array}$

\section{Superscripts}

๘ $\quad$ : Predicted value of $\bullet$

\section{REFERENCES}

1. Cervera, M., Hinton, E., Bonet, J., Bicanic, N., "Nonlinear transient dynamic analysis of three dimensional structures - A finite element program for steel and reinforced concrete materials". In: Hinton, E. (ed.). Numerical methods and software for dynamic analysis of plates and shells. Swansea: Pineridge Press, 1988. 550p. cap. 7, p. 320504.

2. Liu, G.Q. Owen, D. R. J., "Ultimate load behaviour of reinforced concrete plates and shells under dynamic transient loading". International Journal for Numerical Methods in Engineering, v. 22, $\mathrm{N}^{\mathrm{o}}$ 1, pp189-208, 1986.

3. Tamayo, J. L. P., "Análise numérica de vigas mistas pelo método dos elementos finitos". Porto Alegre: PPGEC - Universidade Federal 
do Rio Grande do Sul, 2011 (Tese de mestrado).

4. Beshara, F.B.A. Virdi, K.S., "Nonlinear finite element dynamic analysis of twodimensional concrete structures". Computers and Structures, v. 41, No 6, pp1281-1294, 1991.

5. Cervera, M. Hinton, E., "Análisis dinámico en rotura de estructuras laminares y tridimensionales de hormigón armado”. Revista Internacional de Métodos Numéricos para Calculo y Diseño en Ingeniería, v. $3, \mathrm{~N}^{\circ}$ 1, pp61-76, 1987.

Correspondencia: 1pt.jorge@gmail.com 